\title{
Platelet-Derived Growth Factor Regulates Breast Cancer Progression via $\beta$-Catenin Expression
}

\author{
Yuhki Yokoyama ${ }^{a}$ Seiji Mori ${ }^{a}$ Yoshinosuke Hamada ${ }^{a}$ Miki Hieda ${ }^{a}$ \\ Naomasa Kawaguchi ${ }^{a}$ Mohammed Shaker ${ }^{a}$ Yu Tao $^{a}$ Katsuhide Yoshidome $^{b}$ \\ Masahiko Tsujimoto $^{c}$ Nariaki Matsuura ${ }^{a}$ \\ ${ }^{a}$ Department of Molecular Pathology, Osaka University Graduate School of Medicine and Health Science, and \\ Departments of ${ }^{b}$ Surgery and ${ }^{c}$ Pathology, Osaka Police Hospital, Osaka, Japan
}

\section{Key Words}

Breast cancer $\cdot$ Cancer progression $\cdot \beta$-Catenin $\cdot$ PDGF

\begin{abstract}
Objective: The knowledge on the association between platelet-derived growth factor (PDGF) signaling and epithelial cancers is scarce, although overexpression of PDGF and PDGF receptors has been reported in some human mesenchymal tumors. Thus, we studied the effect of PDGF on breast cancer cells in vitro and the distribution of PDGF in breast cancer tissues. Methods: The effect of PDGF-BB on breast cancer cells was assessed by Western blotting, immunofluorescence, WST and 5-bromo-2-deoxyuridine incorporation experiments. PDGF-B and $\beta$-catenin expression was investigated in breast cancer tissues by immunohistochemistry. Results: PDGF-BB induces $\beta$-catenin expression in breast cancer cells, and immunohistochemically the distribution of PDGF-B was similar to $\beta$-catenin in breast cancer cells. PDGF-B-positive cancer cells were more frequent in cases of ductal carcinoma in situ (87.5\%) than invasive carcinoma (61.2\%). In addition, PDGF-B staining was stronger in intraductal than invasive cancer cells. PDGF-BB tended to
\end{abstract}

induce nuclear translocation of $\beta$-catenin, cell proliferation and DNA incorporation in MDA-MB231 cells, while these results were not found in MCF-7 cells. Conclusion: Our results suggest that PDGF-BB regulates protein expression of $\beta$ catenin and is associated with cancer cell behavior.

Copyright $\odot 2011$ S. Karger AG, Basel

\section{Introduction}

Platelet-derived growth factor (PDGF) was identified as the serum component responsible for the proliferation of mesenchymal cells in the late 1970s [1-4]. The PDGF family consists of four different ligands encoded by different genes: PDGF-A, PDGF-B, PDGF-C and PDGF-D. These ligands form five homo-/heterodimers: PDGF-AA, PDGF-AB, PDGF-BB, PDGF-CC and PDGF-DD. These dimers interact with two receptor tyrosine kinases of PDGF (PDGFRs), PDGFR- $\alpha$ and PDGFR- $\beta$ [5]. It has been considered that PDGF and PDGFRs have a potential role in cancer progression since the transforming gene in the simian sarcoma virus encodes PDGF-B. In fact, overexpression of PDGF and PDGFRs has been reported in

Prof. Nariaki Matsuura, $\mathrm{MD}, \mathrm{PhD}$

Department of Molecular Pathology

Osaka University Graduate School of Medicine and Health Science

Osaka 565-0871 (Japan)

Tel. +81 66879 2591, E-Mail matsuura@ sahs.med.osaka-u.ac.jp 
various human tumors, including gastric, colon, pancreatic, lung and ovarian carcinomas, and gliomas [6-9].

Recently, Yang et al. [10] reported that PDGF-BB facilitates $\beta$-catenin nuclear translocation by blocking $\beta$ catenin phosphorylation following induction of the epithelial-mesenchymal transition in colon cancer.

$\beta$-Catenin is a multiple-function protein that is important for embryogenesis, morphogenesis and cellular differentiation. $\beta$-Catenin acts in a dual manner in epithelial cells, depending on the intracellular localization. At the plasma membrane, $\beta$-catenin is an important component of adherence junctions, acting in cell-cell adhesion by linking E-cadherin, in conjunction with $\alpha$ catenin, to the actin cytoskeleton. However, $\beta$-catenin can also act as the main effector of the canonical WNT signaling cascade in the nucleus. Free cytosolic $\beta$-catenin is quickly degraded by ubiquitination, unless the WNT signaling cascade is activated. Cytosolic $\beta$-catenin assembles with a multiprotein destruction complex, consisting of serine/threonine kinases, casein kinase 1 (CK1), glycogen synthase- $3 \beta$ (GSK3 $\beta$ ), the adenomatous polyposis coli protein and the scaffold protein axin. This destruction complex targets $\beta$-catenin for proteasomal breakdown by CK1- and GSK3 $\beta$-dependent phosphorylation of $\mathrm{N}$-terminal serine/threonine residues [11-16]. In many kinds of cancer, mutations in $\beta$-catenin or destruction complex components induce $\beta$-catenin accumulation in the cytoplasm and nucleus [17].

In breast cancer, overexpression of PDGF, PDGFRs and accumulation of $\beta$-catenin in the cytoplasm and nucleus has been reported [18-20]; however, a possible association between PDGF and $\beta$-catenin has not been clarified.

The main purpose of this paper is to elucidate the effect of PDGF-BB on breast cancer cells focusing on $\beta$ catenin protein expression and distribution.

\section{Materials and Methods}

\section{Cell Culture and Reagents}

The breast cancer cell lines MCF-7 and MDA-MB231 used in this study were obtained from American Type Culture Collection (Manassas, Va., USA). MDA-MB231 cells were grown in Dulbecco's modified Eagle's medium (DMEM; Nissuiseiyaku, Tokyo, Japan) supplemented with $10 \%(\mathrm{w} / \mathrm{v})$ fetal bovine serum (FBS; Biowest, Miami, Fla., USA), $100 \mathrm{U} / \mathrm{ml}$ penicillin and 100 $\mu \mathrm{g} / \mathrm{ml}$ streptomycin (Invitrogen Life Technologies, Carlsbad, Calif., USA) and incubated at $37^{\circ} \mathrm{C}$ in a humidified $10 \% \mathrm{CO}_{2}$ incubator. MCF-7 cells were grown in RPMI-1640 (Nissuiseiyaku) supplemented with $10 \%$ (w/v) FBS, L-glutamine (Nissuiseiyaku), $100 \mathrm{U} / \mathrm{ml}$ penicillin and $100 \mu \mathrm{g} / \mathrm{ml}$ streptomycin, and incubated at $37^{\circ} \mathrm{C}$ in a humidified $5 \% \mathrm{CO}_{2}$ incubator. In previous reports, these cell lines were confirmed to express PDGFR. Recombinant PDGF-BB was purchased from PeproTech (Princeton, N.J., USA). Cycloheximide was purchased from Sigma (St. Louis, Mo., USA).

\section{Immunofluorescence Experiments}

Cells grown on Lab-Tek Chamber Slides (Thermo Fisher Scientific Inc., Waltham, Mass., USA) were fixed with 95\% methanol for $10 \mathrm{~min}$ and then rinsed twice in a phosphate-buffered saline (PBS) and blocked with PBS-10\% bovine serum albumin (BSA) for $30 \mathrm{~min}$ at room temperature. After this procedure, the cells were incubated with a primary antibody $(\mathrm{Ab})$ against $\beta$-catenin (1/800, rabbit-polyclonal Ab; Sigma) at $4{ }^{\circ} \mathrm{C}$ for $16 \mathrm{~h}$. Cells were then incubated with an FITC-labeled anti-rabbit secondary $\mathrm{Ab}$ (1/100; GE Healthcare, Piscataway, N.J., USA) at room temperature for $40 \mathrm{~min}$. Finally, cells were incubated with a propidium iodide (PI) at room temperature for $1 \mathrm{~min}$. Fluorescent signals were detected using a fluorescence microscope (Eclipse E600; Nikon, Tokyo, Japan).

\section{Western Blot Analysis}

Cells were washed twice with cold PBS, lysed in lysis buffer [50 $\mathrm{mm}$ Tris at $\mathrm{pH}$ 8.0, $120 \mathrm{~mm} \mathrm{NaCl}, 1 \mathrm{~mm}$ EDTA, 0.5\% Nonidet P-40 and Proteinase Inhibitor Cocktail Set I (Merck, Darmstadt, Germany)], and rotated at $4^{\circ} \mathrm{C}$ for $30 \mathrm{~min}$. After centrifugation at $15,000 \mathrm{rpm}$ for $5 \mathrm{~min}$ at $4^{\circ} \mathrm{C}$, the supernatant was collected. Protein concentrations were quantitated using the Bio-Rad Protein Assay Dye Reagent Concentrate (Bio-Rad Laboratories, Hercules, Calif., USA) according to the manufacturer's recommendation. Proteins were resolved by SDS-polyacrylamide gel electrophoresis and transferred to a nitrocellulose membrane (Millipore, Billerica, Mass., USA). Membranes were incubated with primary Abs against $\beta$-catenin $(1 / 4,000$, rabbit-polyclonal Ab; Sigma) and GAPDH (1/1,000, mouse-monoclonal Ab; Abcam, Cambridge, Mass., USA) at $4^{\circ} \mathrm{C}$ for $16 \mathrm{~h}$. After washing and incubation with a secondary $\mathrm{Ab}$ (horseradish peroxidase-conjugated anti-mouse or anti-rabbit IgG, $1 / 4,000$, GE Healthcare), protein bands were visualized by the ECL detection system (GE Healthcare). Intensities of $\beta$-catenin and GAPDH bands were measured with ImageJ software (Rasband, WS; ImageJ, National Institutes of Health, Bethesda, Md., USA).

\section{Cell Proliferation Assay}

Cell proliferation was evaluated using a WST-1 proliferation assay. Briefly, $1 \times 10^{3}$ cells of MCF-7 and $2 \times 10^{3}$ cells of MDAMB231 in $100 \mu \mathrm{l}$ of DMEM containing $10 \%$ FBS with or without PDGF-BB (20 ng/ml) were plated into each well of a 96-well plate. After 24 and $48 \mathrm{~h}$ of incubation, $10 \mu \mathrm{l}$ of WST-1 (Wako Pure Chemical Industries, Ltd., Osaka, Japan) solution was added to each well and incubated for $2 \mathrm{~h}$ at $37^{\circ} \mathrm{C}$; absorbance (optical wavelength $415 \mathrm{~nm}$ ) was determined with a microplate reader. The experiments were performed in triplicate.

\section{Bromodeoxyuridine Incorporation Assay}

DNA synthesis as a marker of cellular proliferation was measured by 5-bromo-2-deoxyuridine (BrdU) incorporation using the BrdU Cell Proliferation Assay (Merck) based on incorporation of BrdU into newly synthesized DNA and Ab-mediated detection of BrdU in DNA. Briefly, cells were seeded at a density of 
Fig. 1. Effect of PDGF-BB on $\beta$-catenin expression and localization in breast cancer cells. a Expression of $\beta$-catenin in MCF-7 cells and MDA-MB231 breast cancer cells after PDGF-BB treatment $(20 \mathrm{ng} / \mathrm{ml})$ for $30 \mathrm{~min}$ and $1 \mathrm{~h}$. Protein levels were detected by Western blot, and GAPDH was used as loading control. Arrow indicates the ubiquitinated $\beta$-catenin band. b Effect of cycloheximide pre-incubation on $\beta$ catenin expression by PDGF-BB. MCF-7 cells and MDA-MB231 cells were pretreated with the protein synthesis inhibitor cycloheximide (Chx; $50 \mu \mathrm{g} / \mathrm{ml})$ for $1 \mathrm{~h}$ before treatment with PDGF-BB (20 ng/ml) for an additional hour. $\beta$-Catenin and GAPDH were detected by Western blotting, and GAPDH was used as loading control. The normalized $\beta$-catenin levels against the GAPDH levels are also provided (upper panels).
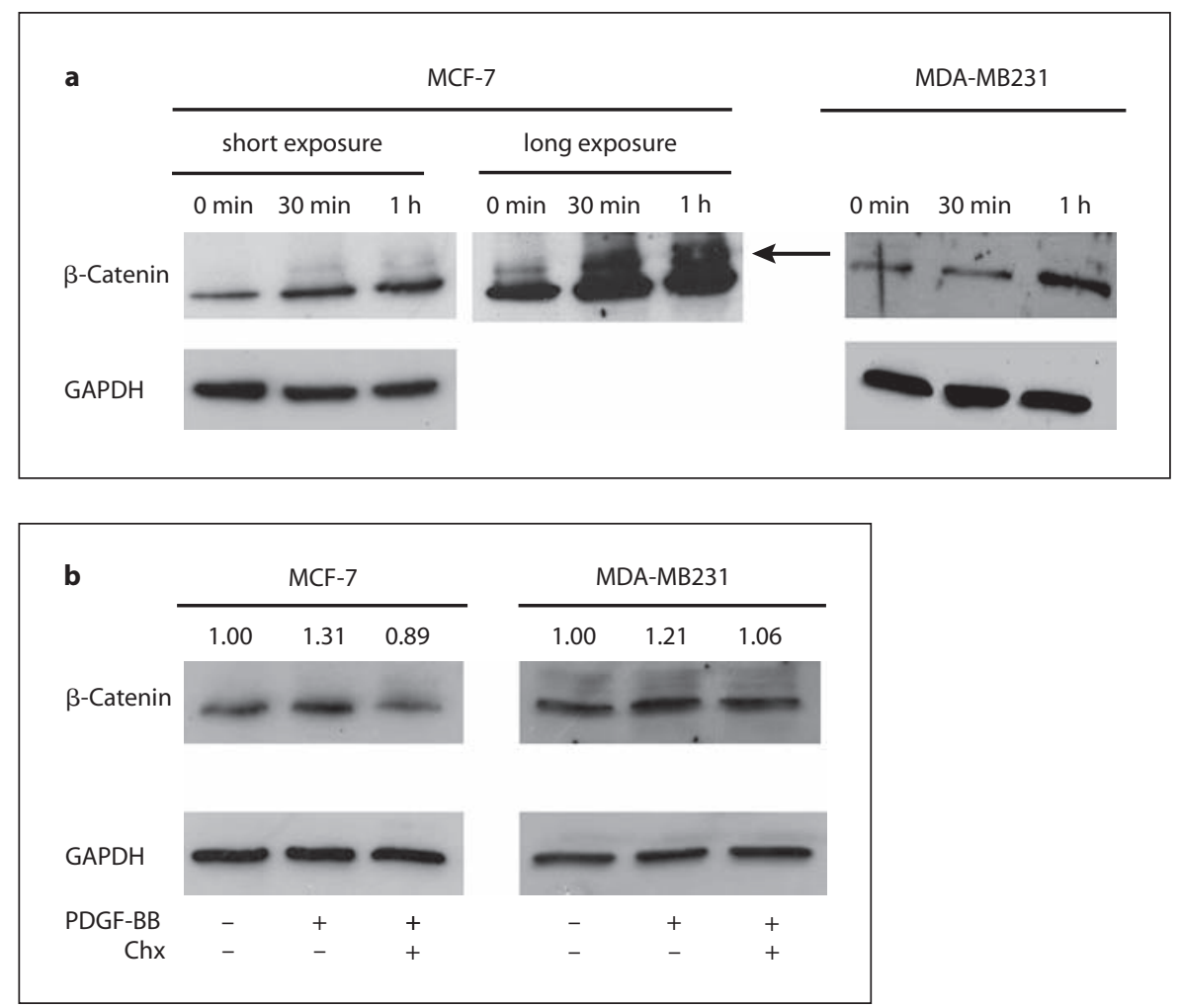

$5 \times 10^{3}$ cells in $100 \mu \mathrm{l}$ of DMEM containing $10 \%$ FBS into each well of a 96 -well plate. PDGF-BB $(20 \mathrm{ng} / \mathrm{ml})$ was added simultaneously or $6 \mathrm{~h}$ before BrdU treatment. After BrdU incubation for $6 \mathrm{~h}$, cells were fixed and DNA was denatured with a fixative/denaturing solution provided by the manufacturer, followed by incubation with BrdU $\mathrm{Ab}$ for $1 \mathrm{~h}$ at room temperature. Immune complexes were detected using 3,3',5,5'-tetramethylbenzidine for $15 \mathrm{~min}$; the reaction was stopped with a stop solution and absorbance at an optical wavelength of $415 \mathrm{~nm}$ was determined with a microplate reader.

\section{Immunohistochemical Staining}

Immunohistochemistry was performed with the avidin-biotin complex method [21] on formalin-fixed, paraffin-embedded tissues of 57 patients with breast cancer surgically treated in the Osaka Police Hospital. Sections $(4 \mu \mathrm{m})$ were deparaffinized in xylene and dehydrated in a graded series of ethanol and processed for antigen retrieval by autoclaving in $0.01 \mathrm{M}$ citrate buffer. Endogenous peroxidase was then blocked by incubating in $3 \% \mathrm{H}_{2} \mathrm{O}_{2}-$ methanol at room temperature for $15 \mathrm{~min}$. After washing with TBS-T and then blocking with TBS-T containing 10\% BSA at room temperature for $30 \mathrm{~min}$, the sections were incubated with primary Abs against $\beta$-catenin (1/800, rabbit polyclonal Ab, Sigma) and PDGF-B chain (1/100, rabbit-polyclonal Ab, Abcam) in TBS-T at $4^{\circ} \mathrm{C}$ for $16 \mathrm{~h}$. The sections were washed three times in TBS-T, incubated with a biotinylated anti-rabbit IgG Ab (1/100; Dako, Glostrup, Denmark) for $40 \mathrm{~min}$ at room temperature. The sections were further incubated with a peroxidase-conjugated streptavidin (1/100, Dako) for $40 \mathrm{~min}$ at room temperature. After washing with TBS-T thoroughly, visualization was developed in 3,3-diaminobenzidine solution (Sigma), then washed and counterstained with a hematoxylin. The immunohistochemical staining of tissues was evaluated based on staining intensity, location and percentage of the cancer cells stained. The percentage of positive cancer cells was graded using the following categories: negative $=0-10 \%$ of cancer cells positively stained; positive $=11-100 \%$ of cancer cells positively stained.

\section{Statistical Analysis}

For cell proliferation and BrdU incorporation assay, Student's $t$ test was used to elucidate the statistical significance of the mean values. The $\chi^{2}$ test was used to analyze the relationship between PDGF-B expression and pathological data. $\mathrm{p}$ values $<0.05$ were regarded as statistically significant.

\section{Results}

\section{PDGF-BB Increases $\beta$-Catenin Expression in Breast Cancer Cells}

As shown in figure 1a, PDGF-BB increased $\beta$-catenin protein expression both in MCF-7 cells and MDA-MB231 cells after 0.5 or $1 \mathrm{~h}$ of stimulation. Additionally, immunofluorescence experiments showed that $\beta$-catenin was detected mainly at plasma membrane level in MCF-7 
C
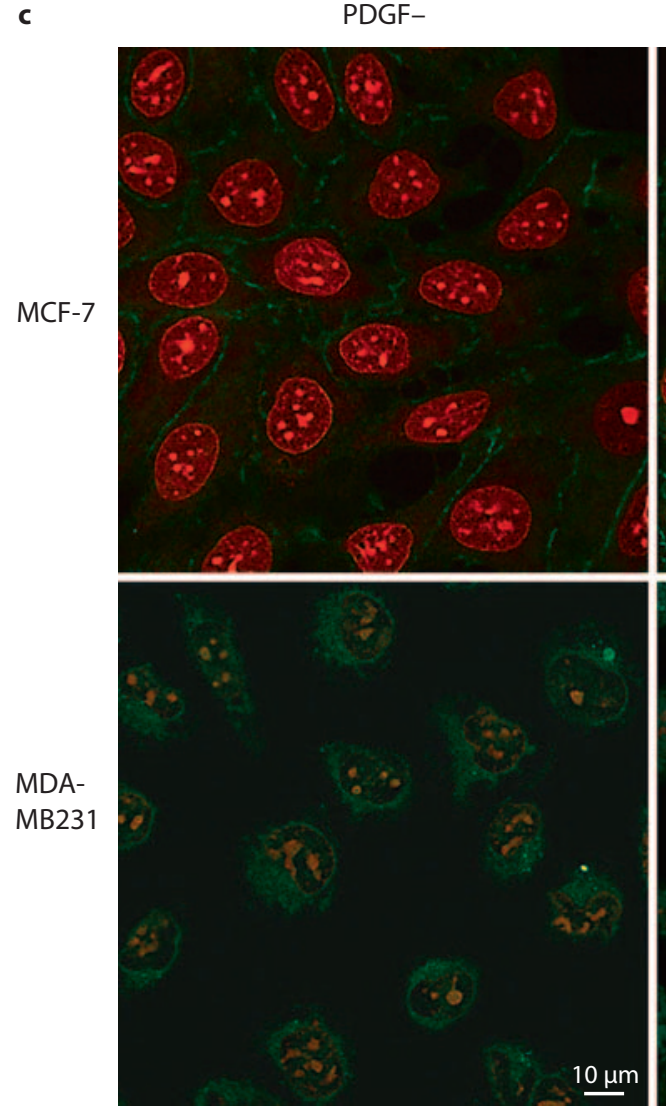

PDGF+
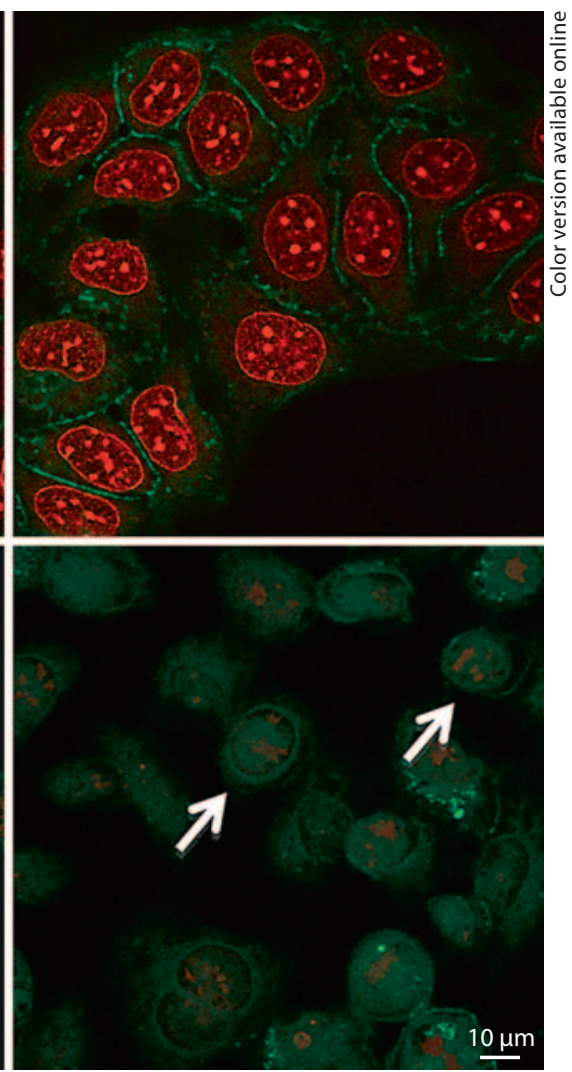

Fig. 1. Effect of PDGF-BB on $\beta$-catenin expression and localization in breast cancer cells. c $\beta$-Catenin distribution after PDGF$\mathrm{BB}$ treatment in breast cancer cell lines. Immunofluorescence analysis of $\beta$-catenin was studied in MCF-7 and MDAMB231 cells treated with PDGF-BB (20 ng/ $\mathrm{ml}$ ) for $1 \mathrm{~h}$. Arrows indicate the plasma membrane and nuclear staining. Nuclei were counterstained with PI (red in the online version). cells, but in MDA-MB231 cells mainly at cytoplasm level with slight nuclear localization (fig. 1c). After $1 \mathrm{~h}$ of PDGF-BB stimulation, fluorescence intensity increased in both cell lines. $\beta$-Catenin distribution did not change notably in MCF-7 cells, although increased nuclear staining was observed in MDA-MB231 cells (fig. 1c).

\section{PDGF-BB Induces de novo $\beta$-Catenin Protein}

Synthesis in Breast Cancer Cells

A previous study reported that a ubiquitinated $\beta$ catenin band can be detected in addition to the $\beta$-catenin band found in Western blotting [22]. PDGF-BB stimulation induces an $8-\mathrm{kD}$-higher band as well as a $94-\mathrm{kD} \beta$ catenin band in MCF-7 cells but not in MDA-MB231 cells (fig. 1a). This result suggests that increased expression of $\beta$-catenin by PDGF-BB is not due to suppression of $\beta$ catenin degradation. Thus, $\beta$-catenin was incubated with the protein synthesis inhibitor cycloheximide before PDGF stimulation to determine whether or not this increased expression of $\beta$-catenin is caused by de novo synthesis. As a result, cycloheximide pre-incubation inhibited increased expression of $\beta$-catenin by PDGF-BB in both breast cancer cell lines (fig. 1b). These results demonstrate PDGF-BB induces de novo $\beta$-catenin protein synthesis in breast cancer cells.

\section{PDGF-BB Promotes Cell Proliferation and DNA \\ Incorporation in Breast Cancer Cells}

WST-1 and BrdU incorporation assays were conducted to investigate cell proliferation and DNA incorporation with or without PDGF-BB in both breast cancer cell lines (fig. 2). Twenty-four or $48 \mathrm{~h}$ after PDGF-BB incubation, cell proliferation was significantly increased in MDA-MB231 but not in MCF-7 cells (fig. 2a, b). Similarly, DNA incorporation was only induced in MDA-MB231 cells after PDGF-BB stimulation for $6 \mathrm{~h}$ (fig. 2c).

\section{PDGF-B Chain Expression Is Associated with \\ $\beta$-Catenin Expression and Cancer Invasion in \\ Breast Cancer Tissue}

To investigate the clinical significance of our results in cultured cells, we performed immunohistochemical analysis of 57 samples of breast cancer and adjacent noncancerous tissues. In non-cancerous regions, PDGF-B 


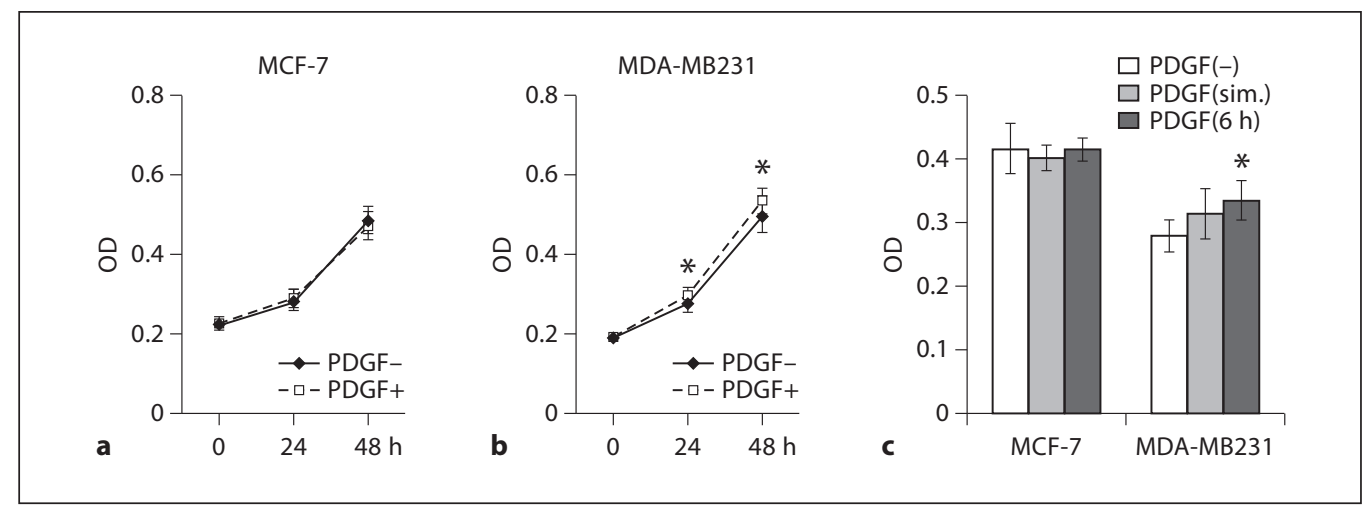

Fig. 2. Effect of PDGF-BB on cell proliferation and DNA incorporation in breast cancer cells. $\mathbf{a}, \mathbf{b}$ Proliferation assay (WST assay) of breast cancer cells. These graphs summarize the relative absorbance $(415 \mathrm{~nm})$ of the proliferation reagent WST-1 for breast carcinoma cell lines MCF-7 (a) and MDA-MB231 cells (b) at 24 and $48 \mathrm{~h}$ in the absence or presence of PDGF-BB $(20 \mathrm{ng} / \mathrm{ml})$. c BrdU assay of breast cancer cells. PDGF-BB (20 ng/ml) was added simultaneously [PDGF(sim.)] or $6 \mathrm{~h}$ before BrdU treatment [PDGF(6 h)]. After BrdU incubation for $6 \mathrm{~h}, \mathrm{BrdU}$ incorporation was detected by the BrdU Cell Proliferation Assay Kit. These graphs summarize the relative absorbance $(415 \mathrm{~nm})$. Data shown are means \pm SD of pooled data of at least 3 experiments each performed in triplicate ( ${ }^{*} \mathrm{p}<0.05$ vs. without PDGF-BB; $t$ test). staining was strong in myoepithelial cells, smooth muscle cells and vascular endothelial cells, with weaker expression in epithelial cells of the mammary duct. Meanwhile, $\beta$-catenin staining was strong in ductal epithelial cells and weak in myoepithelial cells (fig. 3a, b). Figure $3 c-h$ shows PDGF-B and $\beta$-catenin staining in the cancer region. PDGF-B staining in cancer cells was noted in 37 (64.9\%) cases. PDGF-B-positive cancer cells were more frequent in ductal carcinoma in situ (DCIS) cases (87.5\%) than in invasive carcinoma cases (61.2\%). $\beta$-Catenin staining in cancer cells was observed in almost all cases (87.5\%). Although most $\beta$-catenin staining was discovered at the plasma membrane of cancer cells as well as normal cells, in some parts, $\beta$-catenin also stained at cytoplasm and nucleus level (fig. $3 \mathrm{~h}$ ). Similar to PDGF-B, $\beta$-catenin-positive cancer cells were more frequent in DCIS cases $(100.0 \%)$ than in invasive carcinoma cases (85.7\%). In addition, in invasive carcinoma cases, PDGF$B$ and $\beta$-catenin staining was more frequent in intraductal than invasive cancer cells (fig. 3e, f).

As shown in figure 3, most PDGF-B-positive cancer cells showed also strong immunostaining for $\beta$-catenin. In most PDGF-B-negative cancer cells, immunostaining for $\beta$-catenin was weak. Actually, staining scores between two proteins were in agreement in $78.1 \%$. These data are consistent with the results that PDGF-BB induces $\beta$-catenin protein synthesis.

\section{Discussion}

Dysregulation of pleiotropic growth factors, receptors and their downstream signaling pathway components represents a central step in cancer progression. Especially the epidermal, hepatocyte, fibroblast and transforming growth factor $\beta$ pathways contribute to proliferation, anti-apoptosis and invasive behavior of epithelial tumor cells [23]. Meanwhile, PDGF has been shown as an essential factor in mesenchymal cell growth [24-26], and autocrine PDGF signaling has been reported in gliomas and sarcomas. However, less is known about the association between PDGF signaling and epithelial cancers. Therefore, we studied the effect of PDGF on breast cancer cells reported to overexpress PDGF. Yang et al. [10] reported that PDGF-BB induces cancer progression through the $\beta$-catenin nuclear translocation in colon cancer. Thus, we investigated the effect of PDGF-BB on breast cancer cells focusing on $\beta$-catenin expression and distribution. As a result, we found that PDGF-BB induces $\beta$-catenin expression in breast cancer cells (fig. 1). However, PDGF-BB did not notably induce $\beta$-catenin nuclear translocation in breast cancer cells compared to colon cancer (fig. 1c). As mentioned above, $\beta$-catenin forms a complex with GSK3 $\beta, C K 1$, axin and adenomatous polyposis coli protein. This complex induces $\beta$-catenin ubiquitination and destruction in the $26 \mathrm{~S}$ proteosome $[27,28]$. Thus, we tested the levels of ubiquitinated $\beta$-catenin by protein synthesis inhibition to elucidate the mechanism of $\beta$-cate- 
Fig. 3. Immunohistochemical studies for PDGF-B and $\beta$-catenin in breast cancer tissues. Surgical breast cancer specimens were stained with anti-PDGF-B Ab and anti- $\beta$-catenin Ab. Nuclei were counterstained with hematoxylin. a, b PDGF-B and $\beta$-catenin staining in non-cancerous breast tissues. Arrows indicate myoepithelial cells and arrowheads show blood vessels. c, d PDGF-B and $\beta$-catenin staining in ductal carcinoma in situ (DCIS). $\mathbf{e - h}$ PDGF-B and $\beta$-catenin staining in invasive carcinoma. Arrows show intraductal components. Arrowheads show invasive cancer cells.
PFGF-B

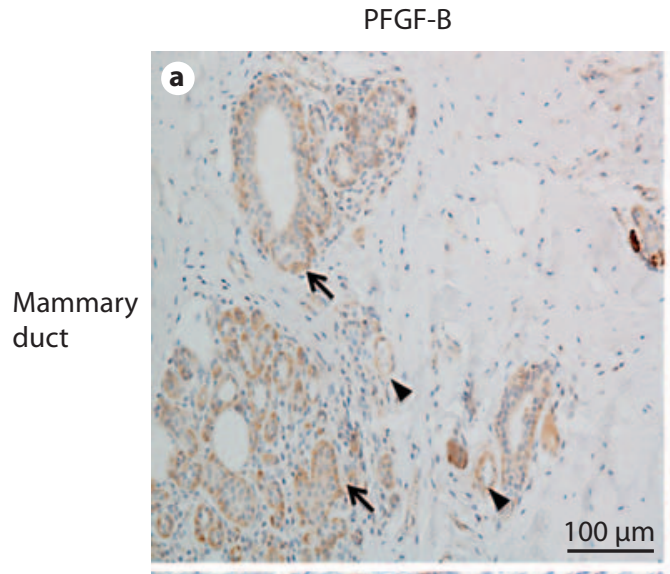

DCIS
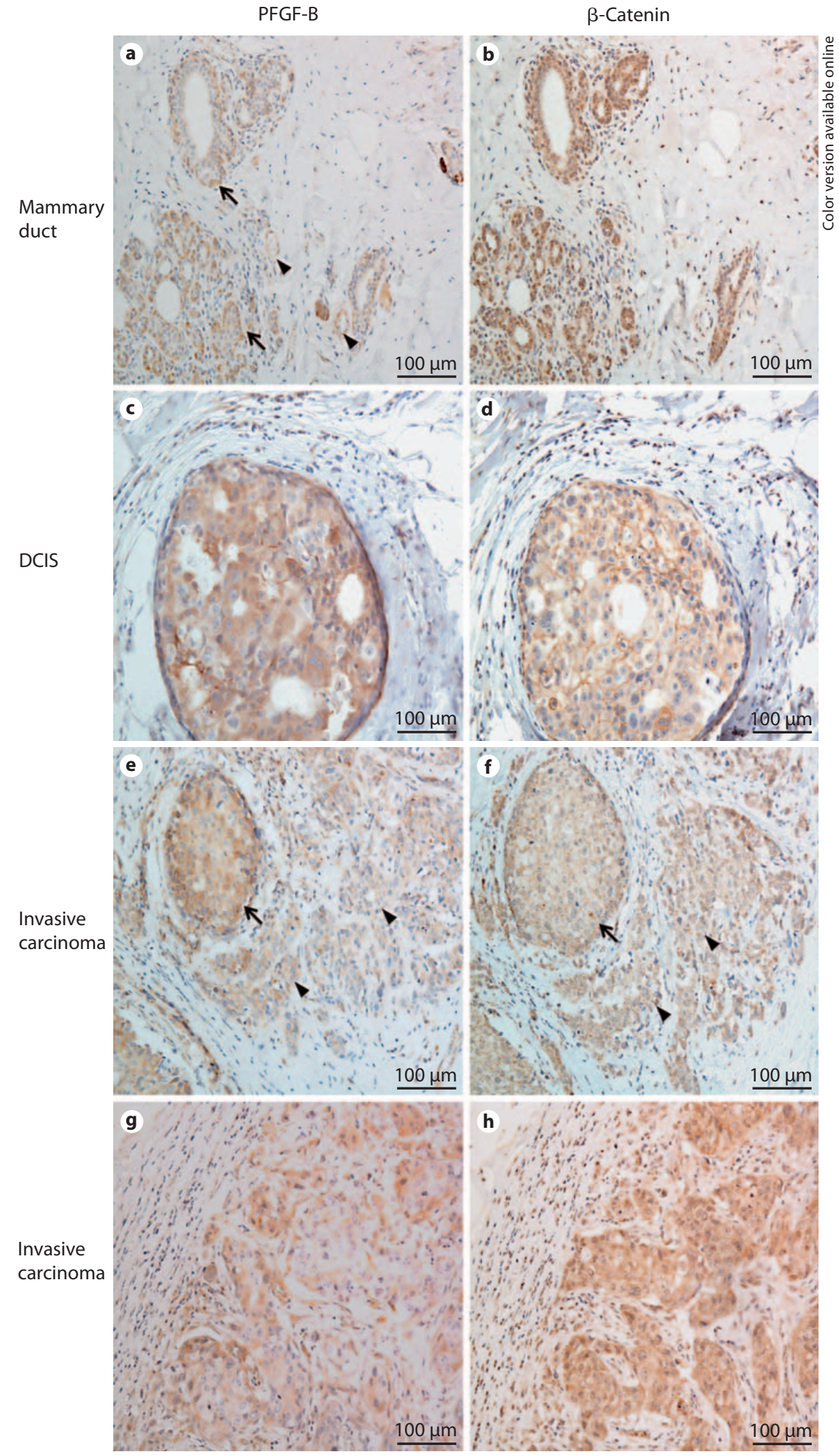
nin elevation. The result was that $\beta$-catenin elevation is caused by de novo protein synthesis (fig. 1). In this regard, Rasola et al. [29] showed that the hepatocyte growth factor upregulates $\beta$-catenin expression via the PI-3 kinase pathway in colorectal cancer cells. Meanwhile, Gosens et al. [30] showed that serum and transforming growth factor $\beta$ induce de novo synthesis of $\beta$-catenin via the $H$-Ras and MEK pathways in smooth muscle cells. Because PDGF also activates the PI-3 kinase and Ras-MAPK pathways [31], PDGF-BB may induce de novo synthesis of $\beta$-catenin via these pathways. Furthermore, Maass et al. [32] reported that PDGF-B overexpression induces $\beta$ catenin upregulation in the liver. These reports suggest that $\beta$-catenin upregulation was induced by PDGF-B also in breast cancer cells.

The role of $\beta$-catenin expression in cancer invasion remains controversial. $\beta$-Catenin accumulation in the nucleus induces epithelial-mesenchymal transition and subsequent cancer invasion [33]. In contrast, in a study by Moreau et al. [34], siRNA-mediated silencing of $\beta$-catenin increased urokinase-type plasminogen activator, urokinase-type plasminogen activator receptor and plasminogen activator inhibitor-1 expression and enhanced the invasive capacity of breast and colon cancer cells. Moreover, Takahashi et al. [35] reported that knockdown of $\beta$-catenin expression with shRNA in B16 melanoma cancer cells enhances the in vitro cell migration potential and reduces cadherin expression. These studies are in accordance with our results that PDGF-B-positive cancer cells were observed in 7 of the 8 (87.5\%) DCIS cases and in 30 of the $49(61.2 \%)$ invasive carcinoma cases, and PDGF-B staining was preferentially detected in intramural cancer cells compared to invasive cancer cells (fig. 3e, f). As shown in figure $3, \beta$-catenin staining at plasma membrane level was strong in most ductal epithelial cells and PDGF-B-positive intraductal cancer cells. In contrast, $\beta$-catenin staining was weak in most PDGF-B-negative invasive cancer cells.

These results lead us to presume that PDGF-BB controls $\beta$-catenin expression and cell-cell adhesion of breast epithelial cells, and loss of PDGF-BB allows cancer cells to acquire an invasive phenotype. In this regard, figure 3 demonstrates that myoepithelial cells highly express PDGF-B in normal mammary ducts. Myoepithelial cells have been called natural tumor suppressors due to their inhibitory effect on tumor progression. These effects are attributed to paracrine factors such as extracellular matrix protein, protease inhibitors and various growth factors. In addition to tumor-inhibitory effects, myoepithelial cells also influence the differentiation and polarity of mammary epithelial cells [36]. Thus, it is presumed that myoepithelial cells regulate cell-cell adhesion of mammary epithelial cells via PDGF-BB secretion. In addition, it is well known that loss of myoepithelial cells in breast cancer participates in the transition from in situ to invasive carcinoma [36]. Hence, PDGF-BB would be one of the key factors involved in this transition due to decreased $\beta$-catenin expression in cancer cells. Taken together, this study indicated that PDGF-BB has a potential role in tumor suppression. Meanwhile, contrary to our hypothesis that PDGF-BB suppresses cancer progression, PDGF-BB slightly induced $\beta$-catenin nuclear translocation, and promoted cell proliferation and DNA incorporation in MDA-MB231 cells, a breast cancer cell line which is more aggressive than MCF-7. It is well known that MCF-7 cells strongly express E-cadherin and MDA-MB231 cells do not [37]. Thus, we assume that the reason for the difference may be attributed to E-cadherin expression, because loss of E-cadherin promotes $\beta$-catenin nuclear translocation. In fact, a tendency to $\beta$-catenin nuclear translocation was noted in MDA-MB231 cells before PDGF-BB stimulation (fig. 1c). Loss of E-cadherin has been reported in breast cancer $[38,39]$. Therefore, in cancer cells with low E-cadherin protein expression, PDGF-BB might induce cancer progression contrary to the E-cadherin-expressing cancer cells. In our study, some PDGF-B-positive cancer cells strongly expressed $\beta$-catenin at cytoplasm and nucleus level (fig. 3g, h), but our results need confirmation by further studies. In conclusion, our results indicate that PDGF-BB is able to regulate $\beta$-catenin expression and is associated with cancer behavior. Although further confirmation of this effect is required, PDGF-BB may be a new prognostic index for breast cancer.
References

Pathobiology 2011;78:253-260 
5 Tallquist M, Kazlauskas A: PDGF signaling in cells and mice. Cytokine Growth Factor Rev 2004;15:205-213.

6 George D: Platelet-derived growth factor receptors: a therapeutic target in solid tumours. Semin Oncol 2001;28:27-33.

7 Nakamura Y, Tanaka F, Yoshikawa Y, Mimori $\mathrm{K}$, Inoue $\mathrm{H}$, Yanaga $\mathrm{K}$, Mori M: PDGF-BB is a novel prognostic factor in colorectal cancer. Ann Surg Oncol 2008;15:2129-2136.

8 Nister M, Libermann TA, Betsholtz C, Pettersson M, Claesson-Welsh L, Heldin $\mathrm{CH}$, Schlessinger J, Westermark B: Expression of messenger RNAs for platelet-derived growth factor and transforming growth factor-alpha and their receptors in human malignant glioma cell lines. Cancer Res 1988;48:39103918.

-9 Nister M, Claesson-Welsh L, Eriksson A, Heldin $\mathrm{CH}$, Westermark B: Differential expression of platelet-derived growth factor receptors in human malignant glioma cell lines. J Biol Chem 1991;266:16755-16763.

-10 Yang L, Lin C, Liu ZR: p68 RNA helicase mediates PDGF-induced epithelial mesenchymal transition by displacing axin from $\beta$ catenin. Cell 2006;127:139-155.

$\checkmark 11$ van Noort, M, Clevers H: TCF transcription factors, mediators of Wnt-signaling in development and cancer. Dev Biol 2002;244:1-8.

$\checkmark 12$ Kikuchi A: Regulation of $\beta$-catenin signaling in the Wnt pathway. Biochem Biophys Res Commun 2000;268:243-248.

-13 Kishida S, Yamamoto H, Ikeda S, Kishida M, Sakamoto I, Koyama S, Kikuchi A: Axin, a negative regulator of the Wnt signaling pathway, directly interacts with adenomatous polyposis coli and regulates the stabilization of $\beta$-catenin. J Biol Chem 1998;273:1082310826.

>14 Turashvili G, Bouchal J, Burkadze G, Kolar Z: Wnt signaling pathway in mammary gland development and carcinogenesis. Pathobiology 2006;73:213-223.

- 15 Liu C, Li Y, Semenov M, Han C, Baeg GH, Tan Y, Zhang Z, Lin X, He X: Control of betacatenin phosphorylation/degradation by a dual-kinase mechanism. Cell 2002;108:837847.

16 Fodde R, Smits R, Clevers H: APC, signal transduction and genetic instability in colorectal cancer. Nat Rev Cancer 2001;1: 55-67.

17 Paul S, Dey A: Wnt signaling and cancer development: therapeutic implication. Neoplasma 2008;55:165-176.
18 Coltrera MD, Wang J, Porter PL, Goan AM: Expression of platelet-derived growth factor $\mathrm{B}$-chain and the platelet-derived growth factor receptor beta subunit in human breast tissue and breast carcinoma. Cancer Res 1995;55:2703-2708.

19 Lin SY, Xia W, Wang JC, Kwong KY, Spohn B, Wen Y, Pestell RG, Hung MC: Betacatenin, a novel prognostic marker for breast cancer: its roles in cyclin D1 expression and cancer progression. Proc Natl Acad Sci USA 2000;97:4262-4266.

20 Toya H, Oyama T, Ohwada S, Togo N, Sakamoto I, Horiguchi J, Koibuchi Y, Adachi S, Jigami T, Nakajima T, Akiyama T: Immunohistochemical expression of the betacatenin-interacting protein B9L is associated with histological high nuclear grade and immunohistochemical ErbB2/HER-2 expression in breast cancers. Cancer Sci 2007;98: 484-490.

21 Tian H, Miyoshi E, Kawaguchi N, Shaker M, Ito $\mathrm{Y}$, Taniguchi N, Tsujimoto $\mathrm{M}$, Matsuura $\mathrm{N}$ : The implication of $\mathrm{N}$-acetylglucosaminyltransferase $\mathrm{V}$ expression in gastric cancer. Pathobiology 2008;75:288-294.

$\checkmark 22$ Aberle H, Bauer A, Stappert J, Kispert A, Kemler R: Beta-catenin is a target for the ubiquitin-proteosome pathway. EMBO J 1997;16:3797-3804.

23 Breuhann K, Longerich T, Schirmacher P: Dysregulation of growth factor signaling in human hepatocellular carcinoma. Oncogene 2006;25:3787-3800.

24 Guha A, Dashner K, Black PM, Wagner JA, Stiles CD: Expression of PDGF and PDGF receptors in human astrocytoma operation specimens supports the existence of an autocrine loop. Int J Cancer 1995;60:168-173.

25 Uhrbom L, Hesselager G, Ostman A, Nister $\mathrm{M}$, Westermark B: Dependence of autocrine growth factor stimulation in platelet-derived growth factor-B-induced mouse brain tumor cells. Int J Cancer 2000;85:398-406.

26 Smits A, Funa K, Vassbotn FS, BeausangLinder M, af Ekenstam F, Heldin $\mathrm{CH}$, Westermark B, Nister M: Expression of plateletderived growth factor and its receptors in proliferative disorders of fibroblastic origin. Am J Pathol 1992;140:639-648.

27 Orford K, Crockett C, Jensen JP, Weissman AM, Byers SW: Serine phosphorylation-regulated ubiquitination and degradation of beta-catenin. J Biol Chem 1997;272:247354738 .
28 Liu J, Stevens J, Matsunami N, White RL: Targeted degradation of beta-catenin by chimeric F-box fusion proteins. Biochem Biophys Res Commun 2004;313:1023-1029.

29 Rasola A, Fassetta M, De Bacco F, D’Alessandro L, Gramaglia D, Di Renzo MF, Comoglio PM: A positive feedback loop between hepatocyte growth factor receptor and $\beta$-catenin sustains colorectal cancer cell invasive growth. Oncogene 2007;26:10781087.

-30 Gosens R, Baarsma HA, Heijink IH, Oenema TA, Halayko AJ, Meurs H, Schmidt M: De novo synthesis of $\beta$-catenin via $H$-Ras and MEK regulates airway smooth muscle growth. FASEB J 2010;24:757-768.

-31 Andrae J, Gallini R, Betsholtz C: Role of platelet-derived growth factors in physiology and medicine. Genes Dev 2008;22:12761312.

\$2 Maass T, Thieringer FR, Mann A, Longerich T, Schirmacher P, Stand D, Hansen T, Galle PR, Teufel A, Kanzler S: Liver specific overexpression of platelet-derived growth factor$\mathrm{B}$ accelerates liver cancer development in chemically induced liver carcinogenesis. Int J Cancer 2011;128:1259-1268.

33 Voulgari A, Pintzas A: Epithelial-mesenchymal transition in cancer metastasis: mechanisms, markers and strategies to overcome drug resistance in the clinic. Biochim Biophys Acta 2009;1796:75-90.

>34 Moreau M, Mourah S, Dosquet C: $\beta$-Catenin and NF- $\kappa \mathrm{B}$ cooperate to regulate the uPA/ UPAR system in cancer cells. Int J Cancer 2011;128:1280-1292.

35 Takahashi Y, Nishikawa M, Suehara T, Takiguchi N, Takakura Y: Gene silencing of betacatenin in melanoma cells retards their growth but promotes the formation of pulmonary metastasis in mice. Int J Cancer 2008;123:2315-2320.

>36 Polyak K, Hu M: Do myoepithelial cells hold the key for breast tumor progression? J Mammary Gland Biol Neoplasia 2005;10: 231-247.

37 Sommers CL, Byers SW, Thompson EW, Torri JA, Gelmann EP: Differentiation state and invasiveness of human breast cancer cell lines. Breast Cancer Res Treat 1994;31:325335.

38 Cowin P, Rowlands TM, Hatsell SJ: Cadherins and catenins in breast cancer. Curr Opin Cell Biol 2005;17:499-508.

>39 Palacios J, Robles-Frías MJ, Castilla MA, López-García MA, Benítez J: The molecular pathology of hereditary breast cancer. Pathobiology 2008;75:85-94. 